\title{
TOD District Planning Based on Residents' Perspectives
}

\author{
Chia-Nung Li ${ }^{1, *}$, Chiang Lin ${ }^{2}$ and Tsu-Kuang Hsieh ${ }^{1}$ \\ 1 Department of Natural Resources, Chinese Culture University, Taipei 11114, Taiwan; \\ xzg@faculty.pccu.edu.tw \\ 2 Graduate Institute of Urban Planning, National Taipei University, New Taipei 23741, Taiwan; \\ pk70609@gmail.com \\ * Correspondence: ljn@ulive.pccu.edu.tw; Tel.: +886-2-2861-0511 (ext. 31434)
}

Academic Editor: Wolfgang Kainz

Received: 19 November 2015; Accepted: 8 April 2016; Published: 14 April 2016

\begin{abstract}
This study uses the MRT (mass rapid transit system) Banqiao Station as an example to explore residents' satisfaction toward transit-oriented development (TOD) living environment characteristics around the Banqiao MRT station. The study uses descriptive statistics, reliability analysis, the factor analysis method and multiple regression analysis to verify the data, and one should expect the study to serve as a reference basis for the government, academia and businesses to formulate urban development and transportation policies. This study shows that residents are mostly satisfied with a 10-minute walk distance to convenience stores. Furthermore, this study uses the factor analysis method and thus brings forth five major TOD factors. With stepwise regression analysis, we discovered that Factors 1 and 2 represent land use and transportation, respectively, while Factor 5 represents high-density development, all of which are significantly related to resident satisfaction. Additionally, gender, age, career, educational background and incomes are individual characteristics that should be forcibly entered into the regression equation. Only Factors 1 and 5 achieve statistical significance. Finally, the study suggests improvements to the surrounding environments of Banqiao Station by focusing on the TOD characteristics of design and density, which can increase TOD residential satisfaction and the public health of residents surrounding the MRT Banqiao Station.
\end{abstract}

Keywords: transit-oriented development; resident satisfaction

\section{Introduction}

For residents that live in the cities north of Taiwan, a current major problem within their residential environment is a lack of appropriate urban planning, resulting in a lack of comfortable, safe and convenient walking spaces and transportation services. Although the major cities in Taiwan have already implemented the concept of transit-oriented development (TOD), their focus was often only on the development of mass rapid transit (MRT), leading to the transportation network service being confined to certain areas. This causes the traffic flow in areas that lack MRT stations to greatly increase during rush hours, consequently causing worse urban congestion and increased air pollution.

Regarding the TOD living environment characteristics, Jing et al. (2010) [1] indicated that the higher density of development, mixed land use, pleasant walking space environment and high quality of public highway transportation services are what the TOD living environment characteristics feature. Sung et al. (2011) [2], however, argued that the provisions of transportation services, land use, street networks and urban design are indispensable conditions. Mu and Jong (2012) [3] emphasized that urban design, governing design, land use, restriction of car use, transportation services and real estate shall instead serve as the evaluation criteria for TOD living environment characteristics. This study integrates the above ideas and suggests that the TOD living environment characteristics shall contain five major aspects, including a high-density living environment, mixed land use environment, 
pedestrian-oriented environment for pleasant walking, a high-quality transport services environment and the far and near surrounding environment to the public transport stations and public facilities. The purpose of higher density land development is to upgrade the development density to increase land use efficiency. The purpose of a mixed land use environment is to provide a wide variety of convenient services for residents, such as shops, banks, shopping centers/malls, parks, etc. The TOD model focuses on the comfortable walking environment, which is due to a belief that the provision of a comfortable, safe, convenient and human-based walking environment is of significant importance. A high-quality transport services environment and the far and near surrounding environments to the public transport stations and public facilities can both increase convenience for residents and increase their satisfaction. In recent years, TOD studies have largely been focused on discussing the effect that TOD has on land use or economic development issues. Currently, most TOD concept designs in Taiwan are produced from the perspective of planners, without studying any correlations between the TOD surrounding living environments and resident satisfaction. Hence, it is important to discuss resident satisfaction, given the knowledge gap in the literature.

Recently, the government has been proactive in developing the New Banqiao Station special district to be a composite four-railroad system station (high-speed rail, heavy rail, mass rapid rail and light rail) and wants it to serve as the new city center. Thus, this study shall take the MRT (mass rapid transit system) Banqiao Station as the case study focus, using 25 TOD living environment characteristics collected from reviewing the literature to serve as the measuring factors. First, it engages a reliability analysis to ensure the results of the questionnaire surveys. Then, based on those descriptive statistics, it intends to determine what the residents feel most satisfied or unsatisfied with in terms of TOD living environment characteristics. Once the descriptive statistics are completed, the 25 TOD living environment characteristics are categorized by using factor analysis; verification by a multiple regression analysis, the study intends to identify the connection between TOD living environment characteristics and resident satisfaction, while simultaneously inputting individual resident characteristics, such as gender, age, job, education level and salary, in order to see if the individual resident characteristics have any influence on resident satisfaction. In the end, it is the sincere wish of the author that the findings of this study can serve as a reference and resource for the government and academia in formulating urban development and transport policies.

\section{Literature Review}

The basic characteristics of the TOD model shall include higher density development, mixed land use, a comfortable walking environment and high-quality public transport services. The density of development is mainly intended to increase the public transport use rate through high-density development of the areas surrounding the station. The main purpose of mixed land use is to increase convenience and the willingness of citizens to use public transportation. The human-oriented urban space is intended to create a comfortable transit environment for walking and additional public space, while also enhancing the service of transfer buses. The high-quality public transport service shall attract existing and potential passengers.

The living characteristics of TOD include the provision of transportation services, land use, street network and urban design. Sung et al. [2] believe that good TOD planning can create a transport-based city. The primary objective of TOD is not to continuously pursue increased density development, but instead, to foster the utility structure of the land surrounding the train station, in addition to adjusting the street network, urban design and a friendly pedestrian environment to serve as an adaptive strategy for the enhancement of a transportation service network.

Mu and Jong (2012) [3] believe that TOD provides a broad future perspective for development by introducing the faster urbanization phenomenon to many other areas, including cities in mainland China, through the TOD model, following a sustainable development model to foster city development. With the development of TOD, urban expansion and citizen accessibility become possible, and issues of improving the railway and bus transfer system shall become feasible, as well. Meanwhile, the 
government is strongly advised to upgrade the urban landscape and pedestrian environment. The TOD shall be accompanied by an intensive and diversified land use pattern to provide quality transportation services and restrict the use of automobiles and cars. Mu and Jong (2012) [3] propose the TOD evaluation criterion characteristics, which include urban design, governing design, land use, restriction of car use, transportation services and real estate, to serve as measurement elements to determine whether Dalian is equipped with the prerequisites of a city. Taking the governing design as an example, the original transportation system and urban planning of Dalian were unable to achieve governing/administering conditions. The planners only focused on the major regions, which caused a lack of coordination within the planning of the urban traffic system, including a lack of public institutes to coordinate the different transport service schedules, transport route maps and passenger fare lists. After introducing the TOD concept to Dalian City, general urban planning and rapid railway transit planning began. The TOD also produced several satellite programs for railway transit and connection with new towns.

The majority of the literature on TOD studies has focused on exploring the effect of TOD on land use. In recent years, many cities in the U.S. have begun to discuss the economic development that is brought forth by the surrounding areas of transport system stations. Denver as an example, by probing the causes of Denver's urbanization. Their findings show that from 1997-2010, Denver adopted TOD characteristics to engage in a railway transport system and high-density, mixed-use development, which greatly upgraded the average level of Denver's urbanization density. The influence resulted in an increase of 180,000 residential housing units, 5,300,000 square feet of retail space, 5,400,000 square feet of office space and 6,200,000 square feet of medical space [4]. Ratner and Goetz (2013) [4] believe that the five major characteristics of a successful TOD model include location, rich mix of choices, value, place-making and transit stations. Location refers to the relative location of the transportation stations to living areas, workplaces, offices, shopping areas, entertainment spots, parks and other local infrastructure. If the station is closer to the above locations, people are more likely to use walking and bike-riding areas, as well as public transportation services. The rich mix of choices refers to a maximum combination of all surrounding living areas, transportation stations and shopping centers/malls, which aim to allow the people living around the TOD stations to enjoy traveling, even in a thoroughly trafficked area, as well as shopping convenience [4]. Value is centered on living areas, shops, offices, shopping centers/malls, entertainment spots, parks, etc., within $500 \mathrm{~m}$ of the TOD station, amounting to a solid value or the sum of the abstract value of people's comfortableness produced by the introduction of the TOD concept. Place-making refers to the importance of selecting a station's location. The old, first-generation transport systems, such as those in Washington D.C., San Francisco and Chicago, have significant and inherent restrictions to developing the TOD concept. For example, the transit stations influence employment, living areas, culture, entertainment, shopping facilities and, consequently, the city's economy.

One of the basic TOD characteristics is the high development-density of land, the purpose of which is to increase land use efficiency by fostering development density. An increase in development density can not only increase the flow of passengers using the public transportation infrastructure and increase the revenue of the transport service providers, but can also increase the number of people in the commercial centers within the region, thus raising the commercial value of such a region. Cervero and Kockelman (1997) [5] mainly adopted the development density, mixed land use and urban design of creating a pedestrian-friendly environment near the transit center as the main TOD planning model. Cervero et al. (2009) [6] used dwelling units per hectare, percentage of land area occupied by buildings, average building floor height and plot ratio as the factors to conduct their research. Sung et al. (2011) [2] considered Seoul as an example to perform a case study on a TOD high-density city. In their study, they also used the sum of residential density, commercial density and office density to estimate the building floor area of land use. The study used building density, architectural volume, residential population, employed population, employment and the percentage of land area occupied by buildings to serve as the density characteristics to estimate the TOD environment characteristics. 
The TOD concept provides many types of convenient services, such as stores, banks, shopping centers/malls, parks/public green spaces, etc., to meet the needs of the residents. Mixed land use can be implemented not just by ground area or multiple buildings within an area, but also within the same building, which is called vertical-mixed land use. Cervero et al. (2009) [6] used the entropy index of land use mix, the proportion of buildings vertically mixed and the proportion of buildings and the double use of total buildings in relation to the total building area to estimate the mixed-use characteristics of TOD environment characteristics. Sung et al. (2011) [2] used land use mix to estimate mixed use and to separate it into two different types for estimation. One type is to use resident and non-resident area to estimate index and land use type. The other is to estimate the diversity by using resident type, commercial type, office type and other types of land use.

Deng and Nelson (2013) [7] believe that if the government has its own budget limit concern, the government can adopt the economical BRT (bus rapid transit) system to solve the problem. The BRT system contains a high-quality transportation service and a cost-effective advantage, such as the BRT Number 1 in Beijing, which significantly increased convenience for the communities close to the city along the BRT highway road network, greatly improving traffic problems in the southern areas. Hence, the author proposes three conclusions from the findings on the basis of the BRT Number 1 project: first, BRT can provide a higher passenger-carrying capacity in faster, more reliable and more comfortable conditions, as compared to conventional bus routes; second, the BRT system can accelerate a change in travel behavior, while the BRT can also serve as important transit locations for improving local transportation; third, an important BRT transit station can produce a positive attraction effect on the residential industry. In addition, the author also suggests that the design of the BRT station itself needs to improve. Using the Beijing station as an example, BRT stations often provide safe pedestrian overhead bridges or underground passages and are equipped with escalators. However, lacking barrier-free accessible elevators, the BRT station becomes inconvenient for special groups of people, such as bicycle riders, the disabled, pregnant women, children and the elderly trying to enter or exit.

Jun et al. (2012) [8] used Seoul as an example for their study. Their findings show that the higher employed population and level of mixed land use help foster better public transportation development. The solution to the high frequency of automobile use is to upgrade the public transport services for local residents, encourage TOD to extend its development to the urban outskirts and encourage citizens to change their behavior patterns when using transportation, such as changing from driving cars to taking public transportation systems. Jun et al. (2012) [8] suggest that the government can implement incentivizing measures to attain a balance between resident area and employment status, which can benefit the factories and enterprises that moved to the urban outskirts and lower the use of personal transportation vehicles.

The TOD model attaches importance to the walking environment, as the TOD spatial scale is mainly measured by the use of walking distance. Thus, the walking environment must be human-based, allowing people to enjoy a comfortable, safe and convenient pedestrian space. Calthorpe (1999) [9] believes that a good walking environment constitutes the most important part of the TOD. Hence, there is a need to create a comfortable walking environment at all starting and stopping points for all of the transport routes and passages. We also need to plant trees along both sides of roads and streets and doors for buildings, which will truly allow the walking environment to become more pedestrian-friendly and foster the TOD.

Frank and Devlin (2010) [10] point out that when living in a community with a good walking environment, one only needs to walk or use public transportation two to three times or more to reduce the use of automobiles by $58 \%$. Furthermore, street connectivity and land use mix can also influence the willingness of residents to walk. Sung et al. (2011) [2] use different types of streets and building patterns to evaluate the degree of convenience for pedestrians and drivers.

Litman (2012) [11] suggests that living in a community with pedestrian and bicycle-riding convenience can help reduce the use of automobiles and improve traffic congestion, greatly contributing to more converged mixed-land development. Jiang et al. (2012) [12] use protection, 
comfort, enjoyment and directness to serve as indicators for evaluating the BRT. One of the indicators refers to traffic safety risks. It is used to evaluate whether or not pedestrians are safe while walking on the pedestrian sidewalk. The findings prove that less than one-third of citizens believe that walking on the sidewalk is safe. Comfort means convenient walking by the pedestrians, including the barrier-free accessibility concept, quality of sidewalk construction and the cleanness and tidiness of the road/street. The findings point out that about $67 \%$ of the citizens in Jinan are satisfied with the comfort of the sidewalks of Jingshi Boulevard. Enjoyment refers to the aesthetic standard, and about $70 \%$ of citizens are satisfied with Jingshi Boulevard's sidewalks. Directness refers to the curvature of the pedestrian sidewalk, the measured data of which comes from a direct survey and on-site collection regarding the curvature of the pedestrian sidewalk and engineering measurement means. The findings indicate that the average coefficient of the BRT sidewalks on Jingshi Boulevard is 1.59; the boulevard itself is 1.36, and the expressway corridor of the BRT is 1.33 , which means that pedestrians need to spend $17 \%-20 \%$ more time to reach the BRT station.

The most important core of TOD will be transport services. Successful TOD relies on the attractiveness of the transport services. Generally, railway transport is the main means of transportation, while road transport is the second most important. In the TOD planning area, land development and transport operation are interdependent. Therefore, the quality of the transport services depends not only on the frequency of dispatching trains and operational efficiency, but also on the design of the bus stop or the building design of the bus transit station, route indicator and schedule coordination between different kinds of transportation means/vehicles. These factors can influence the quality of transportation services. Cervero et al. (2009) use the quantity of public schools, hospitals, public libraries, shopping centers, churches and banks to serve as the indicators for evaluation, while Sung et al. (2011) use the travel time of automobiles or trains from one area to another and the average travel time of taking a train or taxi cab from a specific area to the other CBDs for evaluation $[2,6]$.

The accessibility of public transportation is represented by service quality and convenience for citizens when taking public transportation to a certain location. The study by Cervero et al. (2009) indicates that TOD can decrease the percentage of citizens using personal transportation means, such as cars. The far and near public infrastructure facility environment represents the service quantity of the public infrastructure facilities that can be reached within a certain time unit or the degree of accessibility from the activity or work location to the nearby local public infrastructure facilities. Therefore, the accessibility degree of the location has a huge influence on the distance of travel. People who live far from the public infrastructure facilities tend to be more willing to drive than people living near the public infrastructure facilities. Cervero et al. (2009) [6] use BRT numbers, the shortest distance to the BRT station and the BRT shuttle bus station numbers for measurement reference bases, while Sung et al. (2011) [2] use a fixed train station area for a case study in order to explore the quality of public transportation services and to discuss the connection between the stations and the passengers. For example, the average allocation time for the bus route schedule, the operating number of buses at a speed of less than 20 kilometers per hour, the number of exits of one railroad station and the distance to nearby stations are all considered.

In addition, Olaru and Smith (2011) [13] take the cities of west Australia as the research subject for their case study. The author uses stores, schools, medical centers, entertainment facilities and public transportation facilities for empirical analysis to discuss the factors that make TOD attractive to residents. The findings show that residential locations and transportation facilities closer to the city appear more attractive to residents. However, the study only focuses on the transportation environment and does not explain the real reason that the residents want to continue to live in such locations. Hence, this study shall use the built environment to discuss the degree of satisfaction of residents toward the current TOD living environment characteristics.

According to the above literature regarding the TOD living environment characteristic density in this study, it adopts building density, building volume, resident population, employed population, employment and the percentage of land area occupied by buildings as the density characteristics of 
evaluating the TOD environment characteristics. On the part of the mixed use or the diversity in this study, it adopts mix use, vertical mixing and the balance between residency and business. As for the design, it adopts walking environment, bicycle-riding environment, parking space, parks, green spaces and safety to serve as the design characteristics for evaluating the TOD environment characteristics. As for the high-quality traffic transport service environment, it adopts schooling, medical treatment, office work, leisure and shopping to serve as element factors for measuring the design characteristics of TOD environment characteristics. As for the transferring distance between the public transportation systems, this study uses the bus stops, coach transfer stations, train stations, MRT (subway/metro) stations and taxi stops to serve as the transferring distance characteristics of public transportation for evaluating the TOD environment characteristics.

While studies of TOD and the implementation of TOD have been popular topics in America, Taiwan was stagnating in the reverse planning strategy of "land development guiding public transportation". That is, the location of public transportation systems is determined by the demand of land development, which has further accelerated the arbitrary land development and low-efficiency disposition of land use, forming the developing model of "transit-adjacent development (TAD)". Moreover, current land development in Taiwan is based on "car-oriented development", which generates urban sprawl, and the role of public transportation has accelerated the deterioration of this phenomenon. Because the experience of the development process of metropolitan and transportation policies in Taiwan is similar to that of other countries, Taiwan has recently urged for a policy shift to TOD, in an attempt to solve the current crisis of urban development. Since the first TOD study conducted in Taiwan, there have been more relevant studies proposing the concept and strategy of TOD development. However, there has not been any study of the appropriate target system of TOD in Taiwan; without a common target, TOD becomes a multi-headed strategy and fails to fulfill its fundamental meaning.

In the past, urban development in Taiwan concentrated on road construction, where it encountered similar difficulties. According to the National Energy Conference in 2006, greenhouse gas emissions revealed by the Ministry of Transportation and Communications have been increasing in recent years, and road travel is responsible for $85 \%$ of the emissions in the entire transport division. It is estimated that these emissions will grow four-fold from 1990-2025. Energy consumption accounted for $15.1 \%$ of national energy consumption in 2003 and is the second-largest energy consumption division in Taiwan, but it is worst in terms of the achievement rate of saving energy, at only $28 \%$. Further observation shows that the energy consumption of the road system accounts for $93.4 \%$ of the entire transportation division, while the rail transportation system takes up less than $2 \%$. With regard to road transportation, private cars and motorcycles accounted for a large percentage of energy consumption; the number of small private cars in Taiwan increased significantly from 1971-2003, but the annual growth rate shows a generally descending trend. The high growth rate of the use of automobiles and motorcycles will cause numerous issues, such as an increase in the excessive consumption of fossil fuels, greenhouse and pollution gas emissions and traffic congestion. In addition, in response to the "Kyoto Protocol", which came into effect on 16 February 2005, the issue of the use and possession of private transportation should be the major concern in our country.

Recently, Taiwan has started considering the development of public transportation (particularly a mainstream rail transportation system), such as the Mass Rapid Transit Act in 1988 and the Regulation of Encouraging Public Transportation Development in 2002. However, none of the regulations and related policies mention integration plans for public transportation and land use to resolve the problems. When making policies, the government takes into account the American experience of implementing TOD through the improvement of planning policies and systems to change the previous demand-oriented, unplanned developmental style of land and public transportation, in order to achieve the following policy goals: prevention of unreasonable and inefficient urban expansion, saving public financial expenditure, promoting the effective use of land development, protection of environmental resources, reconstruction of the use of urban space and providing high quality residential environments in the urban space. 
This study refers to the TOD literature proposed by Sung et al. (2011), Mu and Jong (2012) and Ratner and Goetz (2013) [2-4]. This study believes that the above-mentioned 25 TOD living environment characteristics represent five major aspects, including a high-density living environment, mixed land use environment, pedestrian-oriented walking environment, high-quality transporting services environment and the far and near surrounding environments to the public transportation station and public facilities, as shown in Figure 1.

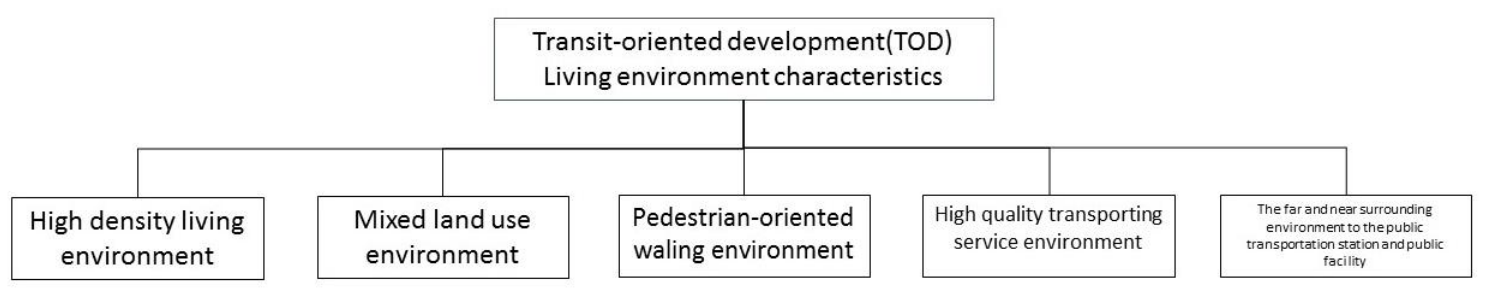

Figure 1. TOD (transit-oriented development) living environment characteristics.

Currently, most of the TOD literature has been aimed at the present city situations and is based on the actual land status characteristics, such as the percentage of land area occupied by buildings, the floor area of the buildings, land use structure entropy index, street density, etc., under which direct enquiries of residents regarding their feelings about their current living environment rarely occur. In city planning, the opinions and thoughts of the residents are very important. Therefore, this study focuses on the perspective of the residents and uses 25 TOD living environment characteristics to understand the satisfaction level of the residents living with such environment characteristics.

\section{Research Design}

The research method and design consist of two major parts. The first is the subject research and analysis, which is the experimental design basis of this study for evaluating satisfaction with the TOD living environment. The second part is the questionnaire survey design, which is an exploration of how to engage data for sampling and how to design the questionnaire survey.

\subsection{How to Evaluate the TOD Living Environment Characteristics?}

According to the literature both at home and abroad on TOD studies, most researchers base their studies on their own experience as planners or expert/scholar questionnaire surveys to conduct their TOD planning design. However, few interviews are performed on residents. The eventual users of the public transportation systems are the residents, and different TOD living environment characteristics generate different feelings in those residents. Therefore, the relevant authorities or the local government should provide a compatible living environment for the residents. Therefore, how to evaluate the TOD living environment characteristics is an important issue for this study [14].

In the review of past literature, although no specific definition was ever established on the TOD living environment characteristics, some scholars have already explored issues related to TOD and residents. For example, Cervero et al. (2009) [6] explore the impact of architectural environments on walking and biking through a case study in Bogota, under which the relations between TOD and walking were discussed. Jing et al. (2010) [1] in their Thinking and Implementation of Commodities Flow along the City Railroad Traffic Routes explore numerous TOD characteristics. Olaru et al. (2011) [13] in their New Transport Corridor, and Resident Location and TOD Transport-oriented Development, explore various TOD and living issues. All of the above studies discuss the TOD living environment or TOD characteristics. This study has taken the above literature and the authors' own viewpoints into account and therefore concludes that TOD living environment characteristics shall center on the mass transit/transport station and cover the area of a high-density living environment (density), highly mixed land use environment (diversity), high-quality pedestrian design walking 
environment (design), high-quality traffic transportation service environment (destination accessibility) and the far and near surrounding environment to the mass transit/transport station (distance to transit) within a 500-meter radius range from the center, as shown in Figure 2.

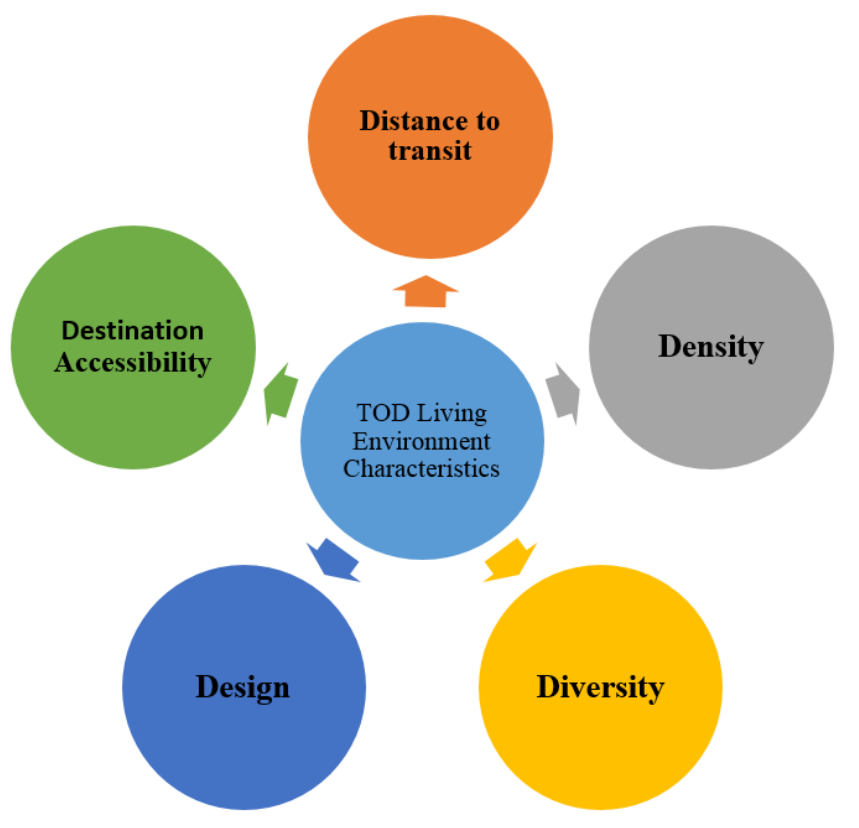

Figure 2. The five characteristics of the TOD living environment.

\subsection{The Relationship between the TOD Living Environment and Residential Satisfaction}

After the questionnaire survey, it is important to identify which econometric model is appropriate in analyzing the impact of TOD environment characteristics on resident satisfaction. Other than using simple descriptive statistics to analyze the collected questionnaire survey results, it is essential to select an additional model that is appropriate for analyzing the relationship between TOD living environment characteristics and resident satisfaction.

Through the literature, we discover that in past studies on residential satisfaction, most adopt statistical analysis for analysis. Figure 3 shows the flowchart of analysis for the present study.

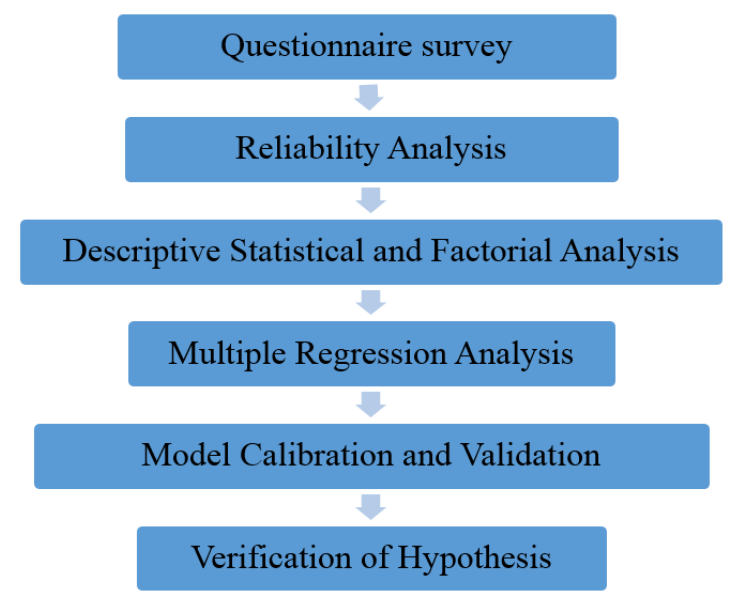

Figure 3. Analysis framework flowchart.

According to the literature review, TOD living environment characteristics represent five major factors, including density (high-density living environment), diversity (mixed land use 
environment), design (pedestrian-oriented walking environment), destination accessibility (the far and near surrounding environment to the mass transit/transport station and public facilities) and distance to transit (high-quality traffic transit/transport environment). This study focuses on the questionnaire-sampled residents living in the surrounding area within a 500-meter radius of Banqiao MRT station as a case study and proposes the following hypotheses.

The TOD highly mixed land use concept offers various convenient services for residents, such as stores, banks, shopping centers, parks and green spaces, etc. The mixed land use concept can be applied to ground floor buildings and diversified buildings. Even in the same building, the concept can still be applied, called vertically-mixed land use. For residents living in such a highly-mixed land use environment, it will be convenient for them in terms of shopping, business engagement, etc. In short, a more highly-mixed land use environment will make the living functions much better and result in more satisfied residents.

If residents live in an area with many transit/transport stations or public facilities, they find it convenient to use the systems (buses, train, etc.) or to engage in business. This will almost certainly lower their use of personal automobiles. Therefore, the far or near distance to the surrounding environment of mass transit/transport station and public facilities shall certainly impact residents' satisfaction with their living environment.

\section{Questionnaire Design}

This study mainly targets TOD living environment characteristics. Therefore, it is necessary to conduct questionnaire interviews. Accordingly, it is important to determine an appropriate questionnaire design and an information framework on the following 5D (density, diversity, design, destination accessibility, distance to transit) in order to truly reflect the actual thinking of the residents and to collect the necessary information materials. Please refer to Figure 4 for the information collection framework.

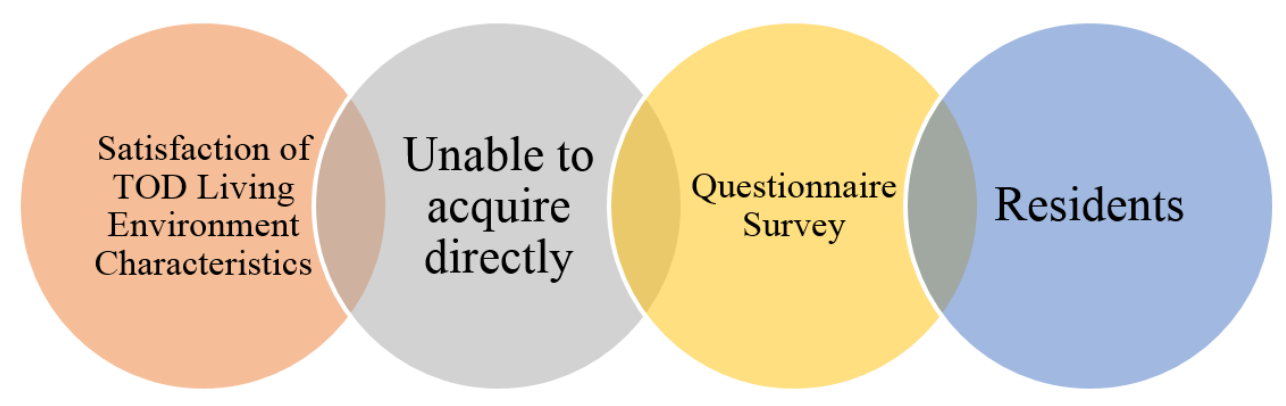

Figure 4. Information collection framework drawing.

This study focuses on the specific area within a 500-meter radius around the new Banqiao Station of the Banqiao District of New Taipei City. First, we determine the exact names of the streets/roads where the above center is located, e.g., Mingchuan Road, Gongguan Street, Xinchan Road, Chanchien Road, for the facilitation of an on-site questionnaire survey. The major questionnaire interview subjects are focused on the local residents. We start from the actual address (i.e., $x x$ Section of $x x$ Road/Street) where the residents reside. We introduce ourselves first, then ask passers-by whether they are local residents and then ask if they would agree to participate in our questionnaire interview. The questionnaire comprises statistical analysis and a five-point Likert scale and quantity table for further research. The questionnaire is divided into three parts: the first part serves as a satisfaction inquiry and investigation to understand to what extent the residents are satisfied with various local TOD living environment characteristics; each question is divided into five levels, from very dissatisfied (one point), to very satisfied (five points), as well as acceptable (three points). The second part is an investigation of overall satisfaction and asks hypothesis questions about the following five subjects, "traffic transportation 
environment", "living environment", "working environment", "leisure environment" and "schooling environment", to see if the residents are satisfied with the overall living environment. The third part is basic information collection from the interviewees, including their gender, age, job, educational background and monthly income, for follow-up statistical information analysis.

This study mainly explores the impact of TOD environment characteristics on resident satisfaction. The data source has to be collected firsthand through questionnaire interviews in order to conduct a complete analysis. TOD environment characteristics mainly derive from previous literature. The TOD environment characteristics include high-density living environment, mixed land use environment, pedestrian-oriented walking environment, high-quality traffic transport services and the far and near distance environment to mass transit/transport station or public infrastructure facilities.

Cervero et al. (2009) and Sung et al. (2011) conducted studies aimed at TOD issues, but most scholars have only focused on the investigation of the current status of urban land use [2,6]. Taking density for example, scholars only calculated the occupied land area by actual buildings, floor area ratio, commercial density, etc. None of the studies ever centered on the viewpoints of the residents, despite the fact that residents' comments and viewpoints constitute a very important part of urban planning and deserve attention. How to plan a living environment that is tailored to the local residents is a very important issue. Therefore, what this study focuses on is not what previous scholars have adopted, which are the values of actual land characteristics for measurement; instead, this study translates such measured values into residents' acknowledgement and satisfaction with land characteristics where they currently reside and explores residents' actual satisfaction. The questionnaire questions and measurement definitions are displayed as follows, in Table 1.

Table 1. Variables for TOD environment characteristics. MRT, mass rapid transit.

\begin{tabular}{|c|c|c|}
\hline Code & Variable & Measurement Scale \\
\hline Y1 & Whether the residents are satisfied with the current living environment as a whole & Sequential order scale \\
\hline $\mathrm{X} 1$ & Neighborhood building density & Sequential order scale \\
\hline $\mathrm{X} 2$ & The height of the neighborhood buildings & Sequential order scale \\
\hline $\mathrm{X} 3$ & The neighborhood resident population density & Sequential order scale \\
\hline $\mathrm{X} 4$ & The population of employed people and employment & Sequential order scale \\
\hline $\mathrm{X} 5$ & The percentage of land area occupied by buildings & Sequential order scale \\
\hline $\mathrm{X} 6$ & The mixed-use degree of business offices & Sequential order scale \\
\hline $\mathrm{X} 7$ & $\begin{array}{c}\text { The vertical mixed-use degree of shopping, residency and leisure entertainment } \\
\text { within a building }\end{array}$ & Sequential order scale \\
\hline $\mathrm{X} 8$ & The balance between residency and business & Sequential order scale \\
\hline X9 & The ratio of entertainment centers and parks & Sequential order scale \\
\hline $\mathrm{X} 10$ & Waling space & Sequential order scale \\
\hline $\mathrm{X} 11$ & Comfort degree of walking & Sequential order scale \\
\hline $\mathrm{X} 12$ & Bike-riding environment & Sequential order scale \\
\hline $\mathrm{X} 13$ & Parking convenience & Sequential order scale \\
\hline X14 & Number of parks and green spaces & Sequential order scale \\
\hline X15 & Degree of traffic accidents occurring & Sequential order scale \\
\hline X16 & 10-min walking distance to the school & Sequential order scale \\
\hline $\mathrm{X} 17$ & 10-min walking distance to the hospital & Sequential order scale \\
\hline $\mathrm{X} 18$ & 10-min walking distance to the government agencies & Sequential order scale \\
\hline X19 & 10-min walking distance to the library & Sequential order scale \\
\hline $\mathrm{X} 20$ & 10 -min walking distance to the stores & Sequential order scale \\
\hline $\mathrm{X} 21$ & 10-min walking distance to the city bus stop & Sequential order scale \\
\hline $\mathrm{X} 22$ & 10-min walking distance to the coach station & Sequential order scale \\
\hline $\mathrm{X} 23$ & 10-min walking distance to the train station & Sequential order scale \\
\hline X24 & 10-min walking distance to the MRT (subway/metro) station & Sequential order scale \\
\hline $\mathrm{X} 25$ & 10-min walking distance to call a taxi & Sequential order scale \\
\hline $\mathrm{Z1}$ & Gender & Nominal scale \\
\hline $\mathrm{Z} 2$ & Age & Nominal scale \\
\hline $\mathrm{Z3}$ & Job & Nominal scale \\
\hline $\mathrm{Z} 4$ & Level of educational background & Sequential order scale \\
\hline $\mathrm{Z} 5$ & Monthly income & Sequential order scale \\
\hline
\end{tabular}

Notes: (1) X1-X25, Y1 represent the variables of satisfaction: more dissatisfied: 1 point; dissatisfied: 2 points; acceptable: 3 points; satisfied: 4 points; more satisfied: 5 points; (2) gender: the gender of interviewed residents (female $=0$, male =1); (3) age: the economic status of interviewees (1, less than 18 years old; 2, between 19 and 25 years old; 3 , between 26 and 35 years old; 4 , between 36 and 49 years old; 5 , between 50 and 59 years old; 6 , between 60 and 64 years old; 7, more than 65 years old); (4) job: the occupation of interviewed residents (1, agricultural, fishery and animal husbandry; 2 , public services and teachers; 3 , financial sector; 4 , industrial sector; 5 , military and police; 6 , service sector; 7, freelancers; 8 , students; 9 , housekeepers; 10 , information sector; 11 , others); (5) level of educational background: the level of educational background of the interviewed residents (1, junior high school and below; 2 , senior high school and vocational school; 3, college; 4, university; 5 , graduate school and above); (6) monthly income: the monthly income of the interviewed residents (Equal to and less than TWD 20,000 = 1; TWD 20,001-30,000 = 2; TWD 30,001-40,000 = 3; TWD 40,001-50,000 = 4; TWD 50,001-60,000 =5; TWD 60,001-80,000 = 6; equal to and greater than TWD 80,001 = 7). 


\section{Model Analysis}

\subsection{Statistical Result of Basic Questionnaire Survey Data}

The total number of people that were interviewed under the questionnaire survey of the Banqiao MRT station was 370, of which there were 364 valid samples and six invalid samples. There were 171 male interviewees, accounting for $47 \%$ of the total interviewees, and 193 female interviewees, accounting for $53 \%$. Fifteen-point-one percent of interviewees were less than 18 years old; $22 \%$ of interviewees were between 19 and 25 years old; $31 \%$ of interviewees were between 26 and 35 years old; $8 \%$ of interviewees were between 36 and 49 years old; $11 \%$ of interviewees were between 50 and 64 years old; and $12.9 \%$ of interviewees were more than 65 years old. In terms of occupation, $30.8 \%$ of interviewees were students; while $12.1 \%$ of interviewees were involved in public services; $9.9 \%$ of the interviewees were from the service sector; and $15 \%$ of the interviewees worked in other occupations. As for the level of educational background, $54 \%$ of interviewees were of college level, and $14 \%$ of interviewees held a master's degree or higher. Concerning income, $28 \%$ of interviewees earned 20,000 TWD/month; 24\% of interviewees earned between 20,001 TWD and 30,000 TWD; and $18 \%$ of interviewees earned an income between 30,001 TWD and 40,000 TWD.

\subsection{Questionnaire Reliability Analysis}

This study expects to discover the quality of the questionnaire survey design through reliability analysis. Therefore, the first part of the questionnaire, survey satisfaction X1-X25, and the second part, overall satisfaction Y1, were verified by using Cronbach's alpha model. The result shows that the total reliability coefficient was 0.871 , confirming that the internal consistency of the questionnaire survey is good enough to support the results of this research.

\subsection{Average Satisfaction of 25 TOD Characteristics}

Table 2 is the satisfaction descriptive statistics table of 25 TOD living environment characteristics, which allow us to know whether the resident is dissatisfied with some current TOD characteristics and also allow us to improve those dissatisfying conditions beforehand, if there are any.

Using 5D categorization to differentiate the top three characteristics, with regard to density, the residents proved more satisfied with building volume, resident population and building density in terms of TOD environment characteristics; on the part of mixed use, the residents proved more satisfied with a balanced residency/business combination, the ratio of entertainment centers and parks and a vertical mix of TOD environment characteristics; on the part of design, the residents are more satisfied with parks/green spaces, parking space and bike-riding TOD environment characteristics; on the part of accessibility, the residents are more satisfied with shopping, schooling and medical care; on the part of distance, the residents are more satisfied with city bus stop, taxi stand and coach transfer station TOD environment characteristics. Therefore, if the government or the planning sector wants to conduct improvements or planning efforts toward individual 5D characteristics, they should be aimed at the improvement and planning of the fourth and fifth ranking places, where the residents are more dissatisfied with the characteristics.

The residents are most dissatisfied with the railway station, MRT (sub/metro) stations, coach transfer station, taxi calling stand, mixed-use, business, walking and bike-riding environments, as well as parking and the walking space. If the government or the planning sector wants to conduct improvements or planning efforts toward all of the TOD characteristics, the first efforts should be made on the above dissatisfaction characteristics. 
Table 2. Satisfaction descriptive statistics table of 25 TOD living environment characteristics.

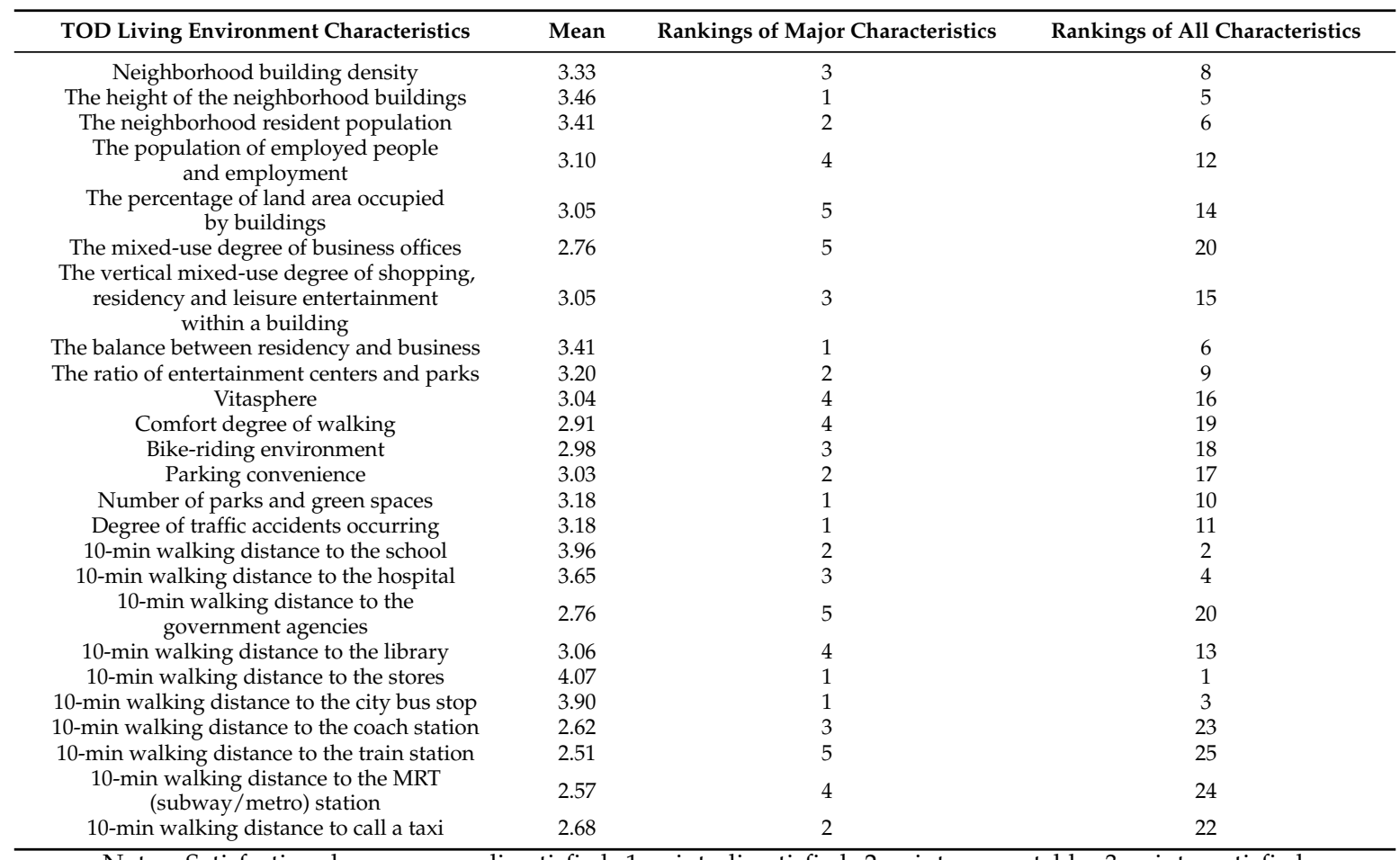

Notes: Satisfaction degree: more dissatisfied: 1 point; dissatisfied: 2 points; acceptable: 3 points; satisfied:

4 points; more satisfied: 5 points.

\subsection{The Factor Analysis}

Since there are many satisfactory items from the 25 living environment characteristics, we use factor analysis to simplify them via principal components analysis and varimax and then extract an eigenvalue of greater than one. The 25 living environment characteristics represent a good result after factor analysis. Furthermore, the Bartlett test value attains a significant level of 0.000 , indicating that these items are suitable for factor analysis.

In addition, from the total variation explaining scale, we understand that of the 25 living environment characteristics, there are six satisfactory components, which are different from this study's five desired components. Therefore, we need to delete more questions, namely questions from the rightmost factors in the statement paper sheet. We delete the sixth component, which states that "the people reside here more than the people who work here in your neighborhood", with the highest factor load of 0.675 . Then, we ran the factor analysis again, getting the KMO (measured by the Kaiser-Meyer-Olkin) statistic value of 0.840 on the remaining 24 living environment characteristics, representing a normal status. Cronbach's alpha values are shown in Table 3.

Table 3. Cronbach's alpha values.

\begin{tabular}{cc}
\hline Factor & Cronbach's Alpha \\
\hline Factor 1 & 0.811 \\
Factor 2 & 0.819 \\
Factor 3 & 0.735 \\
Factor 4 & 0.783 \\
Factor 5 & 0.661 \\
\hline
\end{tabular}

\subsection{Stepwise Regression Analysis}

A stepwise regression analysis is adopted to forecast the living environment satisfaction of the residents living in the area surrounding Banqiao Station via TOD living environment characteristics and 
the residents' personal characteristics. We further establish this study's forecast model of residential satisfaction, as described below.

Here, we set the dependent variable as $y_{1}$ then we set five major factors of TOD living environment characteristics as independent variables using stepwise regression analysis (predictive regression method), and the data results are shown in Table 4 .

Table 4. Model calibration.

\begin{tabular}{|c|c|c|c|c|c|}
\hline Model & $\mathbf{R}$ & $\mathbf{R}^{2}$ & $\operatorname{adj}-R^{2}$ & Altered Values of $\mathbf{R}^{2}$ & $\mathbf{F}$ \\
\hline 1 & 0.400 & 0.160 & 0.157 & 0.160 & $68.786^{* * *}$ \\
\hline 2 & 0.438 & 0.192 & 0.187 & 0.032 & $14.211^{* * *}$ \\
\hline
\end{tabular}

This study adopts a stepwise analysis approach to select an optimal combination of independent variables, and the computer will automatically select the relevant independent variables to enter into the model, which can temporarily avoid collinearity problems.

Land use and transportation design of the first-stage factors can explain $16 \%$ variance values (F change amount of $68.786, p=0.000$ ). After adjustment, R-squared proves to have $15.7 \%$ of explanatory power. Through the gradual analysis approach, we discovered that the coefficients possess only one independent variable and no collinearity problems, which means that the factors of land use and transportation design are independent of other factors' interference.

The second selected independent variable is Factor 5 for density, which can explain $19.2 \%$ variance values (F change amount of 14.211, $p=0.000$ ), satisfying the selection criteria. Model 2 has common factors: land use and transportation design and Factor 5: density's two independent variables. After it is adjusted, it can explain $18.7 \%$ of the variance values, verified with $F$ test results, of which the explanatory power possesses statistical significance. Table 5 shows the regression coefficient table for TOD living environment and living environment satisfaction.

Table 5. The regression coefficient table for TOD living environment characteristics and living environment satisfaction.

\begin{tabular}{|c|c|c|c|c|c|c|c|}
\hline \multirow{2}{*}{ Model } & \multirow{2}{*}{ Coefficient } & \multirow{2}{*}{$\begin{array}{c}\begin{array}{c}\text { Non-Standardized } \\
\text { Coefficient }\end{array} \\
\text { B Estimate Values }\end{array}$} & \multicolumn{2}{|c|}{$\begin{array}{l}\text { Standardized } \\
\text { Coefficients }\end{array}$} & \multirow{2}{*}{$\mathbf{t}$} & \multicolumn{2}{|c|}{ Collinearity } \\
\hline & & & $\begin{array}{l}\text { Standard } \\
\text { Deviation }\end{array}$ & $\begin{array}{c}\text { Beta } \\
\text { Allocation }\end{array}$ & & Tolerance & $\begin{array}{c}\text { Variance Inflation } \\
\text { Factor (VIF) }\end{array}$ \\
\hline \multirow[t]{2}{*}{1} & (Constant) & 1.629 & 0.235 & - & $6.928^{* * *}$ & - & - \\
\hline & Factor 1 (Design) & 0.644 & 0.078 & 0.400 & $8.294^{* * *}$ & 1.000 & 1.000 \\
\hline \multirow[t]{3}{*}{2} & (Constant) & 0.926 & 0.297 & - & $3.117^{* * *}$ & - & - \\
\hline & Factor 1 (Design) & 0.604 & 0.077 & 0.375 & $7.848 * * *$ & 0.981 & 1.019 \\
\hline & Factor 5 (Density) & 0.267 & 0.071 & 0.180 & $3.770 * * *$ & 0.981 & 1.019 \\
\hline
\end{tabular}

After the VIF test, either Model 1 or 2, the variable VIF values are less than 10 and show that there is no significant overlap between the independent variables. The last equation contains two independent variables. The equation is as follows: the residential satisfaction of TOD living environment $=0.926+0.604$ Factor 1 for land use and transportation design +0.267 Factor 5 for density.

By using this equation, we are able to forecast the residential satisfaction of the actual living environment, with an estimated standard deviation of 0.930 . Through the equation's regression coefficients, we can also understand that the greatest impact is Factor 1 for land use and transportation design on the residential satisfaction with the living environment, which is followed by Factor 5 for density. 


\subsection{Personal Characteristics and TOD Living Environment}

Here, we use a forced entry of variance approach to input residents' personal characteristics, gender, age, occupation, level of education and income into the regression model test. Since the personal characteristics of residents belong to the category variables, we must then use the categorical variables, with gender referring to women variable for the reference category; as to the age, we refer to above 65 years old variable as the reference category; for occupation, we refer to other variable for the reference category; for the educational level, we refer to graduate school and above variable for the reference category; for income, we refer to more than NT\$80,001 for the reference category. Meanwhile, we set the dependent variable as $y_{2}$ The independent variables use Factor 1 for design, Factor 2 for high-quality transportation services, Factor 3 for accessibility, Factor 4 for mixed-use and Factor 5 for density. Table 6 summarizes the residential satisfaction of residents' personal characteristics and TOD living environment characteristics.

Table 6. Summary of residents' personal characteristics and TOD living environment.

\begin{tabular}{cccccc}
\hline Model & $\mathbf{R}$ & $\mathbf{R}^{\mathbf{2}}$ & adj-R & Altered Values of $\mathbf{R}^{\mathbf{2}}$ & $\mathbf{F}$ \\
\hline Gender & $0.451(\mathrm{a})$ & 0.204 & 0.190 & 0.204 & $15.202^{* * *}$ \\
Age & $0.454(\mathrm{~b})$ & 0.206 & 0.181 & 0.206 & $8.303^{* * *}$ \\
Job & $0.474(\mathrm{c})$ & 0.225 & 0.192 & 0.225 & $6.740^{* * *}$ \\
Education & $0.461(\mathrm{~d})$ & 0.213 & 0.193 & 0.213 & $10.618^{* * *}$ \\
Income & $0.489(\mathrm{e})$ & 0.239 & 0.215 & 0.239 & $10.044^{* * *}$ \\
\hline
\end{tabular}

Notes: ${ }^{* * *} p$-value $<0.001$.

For gender, we adopt a forced entry approach to engage variable analysis. By doing so, we will discuss all of the variables. Through the forced entry multiple regression equation, we can test each independent variable for the dependent variables' explanatory power. The findings show that if we add a gender-visualized variable into the regression analysis, it significantly enhances the explanatory power. Gender and five TOD living environment characteristic factors have an impact on residential satisfaction, with an overall R-squared interpretation of 0.204 , indicating that five TOD living environment characteristic factors can explain the residential satisfaction of $20.4 \%$ in variance values. After adjustment, the R-squared value is $19.0 \%$ in the interpretation ratio. The model test results point out that the regression effect reaches $F$ change value of 15.202 with statistical significance.

We reviewed two important papers. Firstly, Amérigo and Aragonés (1997) [15] present a theoretical and methodological approach to the study of residential satisfaction, and they seek to give a general view of the relationships established between a person and his/her residential environment.Bonaiuto et al. (1999) [16] test a path model in which residential satisfaction, operationalized in terms of multidimensional perceived residential environment quality (PREQ), predicts neighborhood attachment, which is considered as the final criterion. Socio-demographic (age, sex, socio-economic level) and residential (length of residence both in a neighborhood and in Rome and the number of persons living together) variables are also included in the theoretical model as predictors of both PREQ and neighborhood attachment. Age is an important variable for residential satisfaction, which is highly correlated with occupancy.

Age and five TOD living environment characteristic factors have an impact on residential satisfaction, with an overall R-squared interpretation of 0.206 , indicating that five TOD living environment characteristic factors can explain residential satisfaction effects of $18.1 \%$ in the variance values. After adjustment, the R-squared interpretation ratio is $18.1 \%$. Model test results point out that the regression effect reaches $\mathrm{F}$ change values of $8.303, p=0.000$, with statistical significance. Of the six age-visualized variables, no significant factor is attained, indicating that different ages have no impact on the residential satisfaction evaluation.

When an occupational-visualized variable is added to the regression analysis, it proves that it significantly enhances the explanatory power. Occupation and five TOD living environment 
characteristic factors have an impact on residential satisfaction, with an overall R-squared explanatory power of 0.225 , indicating that five TOD living environment characteristic factors can explain the residential satisfaction effect by $22.5 \%$ of the variance values. After adjustment, the R-squared values possess $19.2 \%$ of the interpretation ratio. The model test results point out that the regression effect reaches $\mathrm{F}$ change values of $6.740, p=0.000$, with statistical significance.

When the education level-visualized variable is added to the regression analysis, it proves that the explanatory power has significantly improved. The educational level and five TOD living environment characteristic factors have an impact on residential satisfaction, with an overall R-squared interpretation of 0.213 , indicating that five TOD living environment characteristic factors can explain the residential satisfaction effect by $21.3 \%$ of the variance values. After adjustment, the R-squared ratio possesses $19.3 \%$ of the explanatory power. The model test results point out that the regression effect reaches $\mathrm{F}$ change values of $10.618, p=0.000$, with statistical significance.

When the salary variable and the income-visualized variable are added to the regression analysis, they significantly enhance the explanatory power. Monthly salary income and five TOD living environment characteristic factors have an impact on residential satisfaction, with an overall R-squared interpretation of 0.239 , indicating that five TOD living environment characteristic factors can explain the residential satisfaction effect by $23.9 \%$ of the variance values. After adjustment, the R-squared explanatory ratio is $21.5 \%$. The model test results point out that the regression effect reaches $\mathrm{F}$ change values of $10.044, p=0.000$, with statistical significance.

Furthermore, with the test of individual independent variables afterwards, we can understand the optimal explanation. Table 7 shows the residents' satisfaction regression coefficient table for residents' personal characteristics and the residential satisfaction of TOD living environment characteristics.

Table 7. Residents' personal characteristics and residential satisfaction.

\begin{tabular}{|c|c|c|c|c|c|}
\hline \multirow{2}{*}{ Reference Category } & \multirow[b]{2}{*}{ Factors } & \multicolumn{2}{|c|}{$\begin{array}{l}\text { Non-Standardized } \\
\text { Coefficients }\end{array}$} & \multirow{2}{*}{$\begin{array}{c}\begin{array}{c}\text { Standardized } \\
\text { Coefficients }\end{array} \\
\text { Beta } \\
\text { Distribution }\end{array}$} & \multirow[b]{2}{*}{ T test } \\
\hline & & B Estimates & $\begin{array}{l}\text { Standard } \\
\text { Deviation }\end{array}$ & & \\
\hline Gender: female & Factor 1: Design & 0.618 & 0.085 & 0.384 & $7.261^{* * *}$ \\
\hline Gender: female & Factor 5: Density & 0.258 & 0.078 & 0.174 & $3.323 * * *$ \\
\hline Age 65 years old and above & Factor 1: Design & 0.617 & 0.086 & 0.383 & $7.188^{* * *}$ \\
\hline Age 65 years old and above & Factor 5: Density & 0.244 & 0.079 & 0.165 & $3.103^{* *}$ \\
\hline Occupation: others & Factor 1: Design & 0.618 & 0.086 & 0.383 & $7.160^{* * *}$ \\
\hline Occupation: others & Factor 5: Density & 0.248 & 0.078 & 0.167 & $3.167^{* *}$ \\
\hline Level of education: graduate level and above & Factor 1: Design & 0.613 & 0.085 & 0.380 & $7.169 * * *$ \\
\hline Level of education: graduate level and above & Factor 1: Density & 0.248 & 0.078 & 0.167 & $3.186^{* *}$ \\
\hline Income of more than NT $\$ 80,001$ & Factor 1: Design & 0.642 & 0.085 & 0.398 & $7.585^{* * *}$ \\
\hline Income of more than NT $\$ 80,001$ & Factor 5: Density & 0.248 & 0.077 & 0.167 & $3.233 * * *$ \\
\hline
\end{tabular}

Regarding gender, we refer to women as the reference category and then further engage afterwards the test of individual independent variables. The coefficient estimates point out that Factor 1 for land use and transportation design has the best explanatory power of the beta coefficient up to 0.384 , indicating that if Factor 1 for land use and transportation design in terms of TOD characteristics of the living environment increases, residents' satisfaction will rise. Secondly, regarding Factor 5 for density, we get a beta coefficient of 0.174 , indicating that if we increase the density of Factor 5 and the TOD living environment characteristics, it will also enhance residents' satisfaction. The last equation will contain six independent variables as follows in Table 7.

In terms of age, we refer to 65 years old and above variable for the reference category. When we further conduct tests on individual independent variables, we get the coefficient estimate results, which indicate that Factor 1 for land use and transportation design has the best explanatory power, with a beta coefficient as high as 0.383 , indicating that if we can increase the TOD residential characteristics of Factor 1 for land use and transportation design for TOD living environment characteristics, we will enhance the residents' satisfaction; this is followed by Factor 5 for density, with a beta coefficient of 
0.165 , indicating that if we increase the TOD living environment characteristics of Factor 5 for density, residents' living satisfaction will be raised.

Regarding occupation, which refers to the other category, the results point out that further tests on the individual independent variable are useful; the coefficient estimates indicate that Factor 1 for land use and transportation design has the best explanatory power, with a beta coefficient as high as 0.383 , showing that if we increase Factor 1 for land use and transportation design for TOD characteristics of the living environment, residents' living satisfaction will improve. This is followed by Factor 5 for density, with a beta coefficient of 0.167 , indicating that if we increase the TOD living environment characteristics of Factor 5 for density, it will also enhance residents' living satisfaction.

Regarding educational level, we refer to graduate level and above. Furthermore, we test the individual independent variable afterwards, and the coefficient estimates point out that Factor 1 for land use and transportation design has the best explanatory power, with a beta coefficient as high as 0.380, indicating that if we increase the TOD living environment characteristics of Factor 1 for land use and transportation design, the residents' living satisfaction will be enhanced; this is followed by Factor 5 for density, with a beta coefficient of 0.167 , indicating that if we increase the TOD living environment characteristics of Factor 5 for density, we will enhance residents' living satisfaction.

In terms of income, we refer to more than NT\$80,001 for the reference category. Further tests afterwards on individual independent variables prove that the coefficient estimate results indicate that Factor 1 for land use and transportation design has the best explanatory power, with a beta coefficient as high as 0.398 , showing that if we can increase the TOD living environment characteristics of Factor 1 for land use and transportation design, we will enhance residents' living satisfaction. Next, this is followed by Factor 5 for density, with a beta coefficient of 0.167 , indicating that if we increase the TOD living environment characteristics of Factor 1 for density, we will also enhance residents' living satisfaction.

\section{Conclusions}

This study found that residents within a 10-min walking distance to the stores of TOD living environment characteristics are the most satisfied with the living environment; residents within a 10-min walking distance to the railway station of TOD living environment characteristics are the least satisfied. If ranking the arrangement of five major TOD characteristics, density, residents' viewpoints toward building volume, residents' viewpoints toward resident population and building density of TOD living environment characteristics are more satisfactory; regarding mixed-use, the residents' viewpoints toward a balanced ratio of residency and businesses, the ratio of entertainment centers and parks, and a vertical mix of TOD living environment characteristics are more satisfactory; regarding design, residents' viewpoints toward parks, green spaces, parking and the bike-riding environment of TOD living environment characteristics are more satisfactory; regarding accessibility, residents' viewpoints on shopping, schooling and medical treatment, the TOD living environment characteristics are more satisfactory; regarding distance, residents' viewpoints toward urban bus stops, taxi-calling stands, and coach transfer stations of TOD living environment characteristics are more satisfactory. If we use all of the TOD living environment characteristics for satisfaction sorting order, the least satisfactory for the residents includes train station, MRT stations, coach transfer station, taxi-calling stand, mixed-use, office, walking, bike-riding, parking and Vitasphere. Assuming that the future effort for the government or planning departments is to improve the living environment for TOD characteristics, it is recommended that the first efforts target the least satisfied 5D characteristics or what the residents consider the least satisfactory characteristics.

By using factor analysis, we get five major factors for TOD living environment characteristics, including Factor 1 for land use and transportation design, named "design", with eight TOD living environment characteristics, such as "sufficient parking spaces for automobiles", "bike-riding environment", "comfortable pedestrian sidewalks with no motorcycles illegally parked nearby", "collision of bikes and motorcycles", "not too converged buildings", "buildings are not too high or 
too big", "parks are enjoyable and attractive" and "the area of the park is larger than that of the entertainment center."

Since Factor 2 concerns public transportation, it has been named "distance to transit", with six TOD living environment characteristics, including 10-min walking distance to the "coach transfer station", "railway station", "subway station", "taxi-calling stand", "the municipal government and district office", "libraries, concert halls", etc. Factor 3 concerns offices and business and is hence named "destination accessibility", including four TOD living environment characteristics, such as 10-min walking distance to "stores or market", "bus stop", "school" and "hospital or clinic." Factor 4 concerns shopping and is hence named "diversity", with two TOD living environment characteristics, including "shopping centers and entertainment centers" and "shopping, residential, leisure and entertainment businesses or homes." Factor 5 concerns density and is therefore named "density", with four TOD living environment characteristics, including "nine-to-five workers", "residents", "buildings" and "offices and business buildings."

After factor analysis, we used a forecast regression model and found that of the TOD living environment characteristics, only Factor 1 for land use and transportation design and Factor 5 for density are significant. The residential satisfaction of TOD living environment characteristics $=0.926,+0.604$ Factor 1 for land use and transportation design, +0.267 Factors 5 for density. Therefore, if government departments want to engage in efforts to improve the living environment for TOD characteristics, it is recommended that they target Factor 1 for land use and transportation design characteristics, which include eight TOD living environment characteristics for their priority improvement strategy.

If we include the resident characteristics and adopt a forced entry approach for validation, we can only get Factor 1 for land use and transportation design and Factor 5 for density, which can attain a significant level and are positively correlated. In terms of other residents' personal characteristics, they prove insignificant. Our findings are generalized in Table 8.

Table 8. Study findings for residents' satisfaction with TOD living environment characteristics.

\begin{tabular}{|c|c|c|c|}
\hline Items & Statistical Methods & Purpose & Results \\
\hline 2 & $\begin{array}{l}\text { Multiple regression } \\
\text { analysis: forced } \\
\text { entry approach }\end{array}$ & $\begin{array}{l}\text { To establish a forecast } \\
\text { model on residential } \\
\text { satisfaction for this } \\
\text { study and add residents' } \\
\text { personal characteristics }\end{array}$ & $\begin{array}{c}\text { Regardless of gender, age, occupation, educational } \\
\text { level and salary income, when added with residents' } \\
\text { personal characteristics, only Factor } 1 \text { for land use and } \\
\text { transportation design and Factor } 2 \text { for density } \\
\text { prove significant. }\end{array}$ \\
\hline
\end{tabular}

The scope of research shall center on the newly-assigned Banqiao District of New Taipei City (Xin-Ban Special District) within a 500-meter radius from the center. The so-called Xin-Ban Specific District Area features a combination construction of integrated four-railroad systems, containing an area of 10,000 hectare of parks, one large square, the Grand Taipei Opera House, the Convention \& Exhibition Center, tourist hotels and shopping complex centers or shopping malls. Compared to other cities and counties of the current development type, this area possesses considerable advantages. Therefore, in the research planning stage, it is highly recommended that appropriate importance be attached to the local development characteristics in order to avoid inconsistency in the area's development, which may in turn cause inappropriate misinterpretations or mistakes for urban and rural development planning. 
Acknowledgments: Thanks to the Ministry of Science and Technology, Taiwan (R.O.C.), for funding our research. Project Number NSC 101-2410-H-034-046.

Author Contributions: This research was designed and written by Chia-Nung Li. The data were analyzed by Chia-Nung Li and Chiang Lin. The authors approved the final manuscript.

Conflicts of Interest: The authors declare no conflict of interest.

\section{References}

1. Jing, B.; Shengwen, L.; Xiao, Y. Urban Rail Transit along the Property: Thinking and Practice; Xi-an Jiaotong University Press: Xi'an, China, 2010.

2. Sung, H.; Oh, J.-T. Transit-oriented development in a high-density city: Identifying its association with transit ridership in Seoul, Korea. Cities 2011, 28, 70-82. [CrossRef]

3. Mu, R.; Jong, M.D. Establishing the conditions for effective transit-oriented development in China: The case of Dalian. J. Transp. Geogr. 2012, 24, 234-249. [CrossRef]

4. Ratner, K.A.; Goetz, A.R. The reshaping of land use and urban form in Denver through transit-oriented development. Cities 2013, 30, 31-46. [CrossRef]

5. Cervero, R.; Kockelman, K. Travel demand and the 3Ds: Density, diversity, and design. Transp. Res. Part D Transp. Environ. 1997, 2, 199-219. [CrossRef]

6. Cervero, R.; Sarmiento, O.L.; Jacoby, E.; Gomez, L.F.; Neiman, A. Influences of built environments on walking and cycling: Lessons from bogota. Int. J. Sustain. Transp. 2009, 3, 203-226. [CrossRef]

7. Deng, T.; Nelson, J.D. Bus rapid transit implementation in Beijing: An evaluation of performance and impacts. Res. Transp. Econ. 2013, 39, 108-113. [CrossRef]

8. Jun, M.J.; Kim, J.I.; Kwon, J.H.; Jeong, J.E. The effects of high-density suburban development on commuter mode choices in Seoul, Korea. Cities 2013, 31, 230-238. [CrossRef]

9. Calthorpe, P. The Next American Metropolis: Ecology, Community, and the American Dream; Princeton Architectural Press: Princeton, NJ, USA, 1993.

10. Frank, L.D.; Devlin, A. Neighborhood Design, Travel, and Health in Metro Vancouver: Using a Walkability Index; UBC Active Transportation Collaborator: Vancouver, BC, Canada, 2010.

11. Litman, T. Comprehensive evaluation of energy conservation and emission reduction policies. Transp. Res. Part A Policy Pract. 2013, 47, 153-166. [CrossRef]

12. Jiang, Y.; Christopher Zegras, P.; Mehndiratta, S. Walk the line: Station context, corridor type and bus rapid transit walk access in Jinan, China. J. Transp. Geogr. 2012, 20, 1-14. [CrossRef]

13. Olaru, D.; Smith, B. Residential location and transit-oriented development in a new rail corridor. Transp. Res. Part A Policy Pract. 2011, 45, 219-237. [CrossRef]

14. Zhang, M.; Wang, L. The impacts of mass transit on land development in China: The case of Beijing. Res. Transp. Econ. 2013, 40, 124-133. [CrossRef]

15. Amérigo, M.; Aragonés, J.I. A theoretical and methodological approach to the study of residential satisfaction. J. Environ. Psychol. 1997, 17, 47-57. [CrossRef]

16. Bonaiuto, M.; Aiello, A.; Perugini, M.; Bonnes, M.; Ercolani, A.P. Multidimensional perception of residential environment quality and neighbourhood attachment in the urban environment. J. Environ. Psychol. 1999, 19, 331-352. [CrossRef]

(C) 2016 by the authors; licensee MDPI, Basel, Switzerland. This article is an open access article distributed under the terms and conditions of the Creative Commons Attribution (CC-BY) license (http://creativecommons.org/licenses/by/4.0/). 